\title{
Lyso-PAF acetyltransferase activity in neutrophils of patients during acute asthma and after recovery
}

\author{
N.L.A. Misso*, R.L. Gillon*, G.A. Stewart**, P.J. Thompson*
}

Lyso-PAF acetyltransferase activity in neutrophils of patients during acute asthma and after recovery. N.L.A. Misso, R.L. Gillon, G.A. Stewart, P.J. Thompson. (CERS Journals Ltd 1996.

ABSTRACT: The production of platelet-activating factor (PAF) by inflammatory cells is regulated by lyso-PAF acetyltransferase, and the activity of this enzyme is increased in neutrophils of stable asthmatic patients. The aim of this investigation was to determine whether acetyltransferase activity is further upregulated in asthmatic patients experiencing acute symptoms.

A radioenzymatic assay was used to measure the enzymatic affinity constant $(\mathrm{Km})$ and maximal enzymatic activity (Vmax) for acetyltransferase from unstimulated and $\mathrm{Ca}^{2+}$ ionophore (A23187)-stimulated neutrophils from 16 patients with acute asthma, and the measurement was repeated at the time of discharge $(n=9)$ and after recovery from the acute episode $(n=13)$.

During acute asthma, $\mathrm{Km}$ (median 93.8 (interquartile range 64.1-109.7) $\mu \mathrm{M}$ ) was lower than that measured in nonasthmatic subjects in a previous study using identical methods (155.1 (122.2-179.9) $\mu M ; p=0.0001)$, and in 10 out of 13 acute patients $\mathrm{Km}$ for unstimulated neutrophils increased following recovery. In A23187-stimulated neutrophils, $\mathrm{Km}$ during acute asthma $(84.3(73.6-100.2) \mu \mathrm{M})$ and at discharge (83.9 (83.1-94.8) $\mu \mathrm{M})$ were similar, but $\mathrm{Km}$ after recovery was increased $(115.0$ (95.6-119.5) $\mu \mathrm{M} ; \mathrm{p}=0.02)$. The change in $\mathrm{Km}$ following stimulation with $\mathrm{A23187}$ was also significantly less during acute asthma than previously measured in nonasthmatic subjects $(\mathrm{p}=\mathbf{0 . 0 0 3})$. Although $V_{\max }$ during acute asthma (12.9 (interquartile range $10.5-22.5) \mathrm{nmol}^{-} \mathrm{min}^{-1} \cdot \mathrm{mg}^{-1}$ protein) did not differ significantly from that at discharge $\left(14.4(12.3-20.4) \mathrm{nmol}^{-} \mathrm{min}^{-1} \cdot \mathrm{mg}^{-1}\right)$ or after recovery $(17.3(12.3-18.4)$ nmol·min-1 $\cdot \mathrm{mg}^{-1}$ ), both median $\mathrm{Km}_{\mathrm{m}}$ and $\mathrm{V}_{\mathrm{max}}$ tended to be lowest during acute asthma and increase at discharge and after recovery.

An increase in lyso-PAF acetyltransferase activity alone may not account for increased systemic PAF concentrations during acute asthma. However, the reduction in the enzymatic affinity constant and its smaller change following in vitro stimulation suggest that alterations in the affinity of acetyltransferase for acetylcoenzyme $A(\mathrm{CoA})$ and in the regulation of enzyme activity may be occurring during acute asthma.

Eur Respir J., 1996, 9, 2243-2249.
Asthma and Allergy Research Unit, Depts of *Medicine and $* *$ Microbiology, University of Western Australia, Queen Elizabeth II Medical Centre, Perth, Australia.

Correspondence: P.J. Thompson Asthma and Allergy Research Unit University Dept of Medicine Queen Elizabeth II Medical Centre Nedlands WA 6009

Australia

Keywords: Acetyltransferase asthma

neutrophils

platelet-activating factor

Received: December 291995 Accepted after revision June 301996
Platelet-activating factor (PAF) is an ether-linked phospholipid with numerous biological activities which suggest that it plays a significant role in the pathogenesis of asthma [1]. PAF causes bronchoconstriction and, in some studies, has been shown to induce a persistent increase in bronchial hyperresponsiveness in humans [2, $3]$. This may relate to the potency of PAF as a chemoattractant for eosinophils [4], since these cells appear to play a significant role in the development of airway hyperresponsiveness [5, 6]. However, other studies, both in normal and asthmatic subjects [7, 8], have failed to demonstrate any increase in airway responsiveness after PAF inhalation. PAF also causes airway microvascular leakage and oedema [9], stimulates tracheal mucus secretion [10], and inhibits mucociliary clearance in normal subjects [11].

There is much indirect evidence implicating PAF in the pathogenesis of asthma, but it has been more difficult to obtain direct evidence based on measurements of this mediator and its precursor, lyso-PAF, in biological fluids [12]. However, PAF has been detected in bronchoalveolar lavage fluid (BAL) from asthmatics [13], and allergen challenge has resulted in high levels of lyso-PAF in nasal fluids [14], and increased plasma PAF concentrations [15]. A number of recent studies have also suggested that systemic PAF concentrations may be increased in symptomatic asthmatic subjects [16-18]. Despite these observations, the interpretation of such measurements is complicated by factors such as the short half-life of PAF, the fact that lyso-PAF is both a precursor and metabolite of PAF, the likelihood that PAF acts mainly at localized sites of inflammation and that it may be rapidly metabolized and reincorporated by surrounding inflammatory cells [19].

PAF is synthesized by a variety of cell types, including neutrophils, eosinophils, alveolar macrophages, monocytes and endothelial cells, in response to stimuli, such as the calcium ionophore A23187, opsonized zymosan 
[19], granulocyte/macrophage colony-stimulating factor (GM-CSF) [20], bradykinin, tumour-necrosis factor- $\alpha$ $(\mathrm{TNF}-\alpha)$ and interleukin- $1 \alpha(\mathrm{IL}-1 \alpha)$ [21, 22]. Stimulated inflammatory cells synthesize PAF in a two-step process catalysed by the enzymes phospholipase $\mathrm{A}_{2}$ and acetylcoenzyme-A (CoA):lyso-PAF acetyltransferase [23]. Acetyltransferase activity can be increased in vitro by A23187, TNF- $\alpha$ and IL- $1 \alpha$, and in vivo activation of this enzyme could result in the production of excessive amounts of PAF [19]. Thus, upregulation of acetyltransferase activity may possibly explain the increased PAF concentrations reported in some studies of symptomatic asthmatics.

In a previous study from our laboratory, increased acetyltransferase activity was observed in neutrophils from clinically stable atopic asthmatic subjects compared with nonasthmatic control subjects, suggesting that in these nonsymptomatic asthmatics, neutrophils may be subject to chronic priming [24]. It is not clear, however, whether disease exacerbation further modulates acetyltransferase activity. Thus, the aim of the present investigation was to measure neutrophil acetyltransferase activity in a group of asthmatic subjects experiencing acute disease exacerbations.

\section{Methods}

\section{Subjects}

Sixteen subjects presenting to the Emergency Department with a clinically diagnosed acute exacerbation of asthma were recruited for the study, which was approved by the Committee for Human Rights of the University of Western Australia. Informed consent was obtained from all patients in the study group which comprised 13 females and 3 males (mean age $39 \pm 15$ yrs, range 19-69 yrs). The clinical details and drug treatments were noted for all patients, and spirometry and oximetry data were obtained for most patients (table 1). Patients were bled prior to receiving treatment and a second blood sample was obtained at the time of discharge from those patients admitted to hospital $(n=9)$. A further blood sample was obtained from patients $(n=13)$ approximately 8 weeks after the acute exacerbation, when their asthma was considered to be stable and they had not been taking oral corticosteroids for at least 2 weeks. Three subjects could not be contacted after discharge and it was, therefore, not possible to obtain a follow-up blood sample from these subjects.

\section{Isolation of neutrophils}

Whole blood, anticoagulated with ethylenediamine tetra-acetic acid (EDTA), was layered on a discontinuous Percoll gradient (densities 1.082, 1.094) and centrifuged $(500 \times \mathrm{g}$ for $30 \mathrm{~min})$. The neutrophil band was recovered and contaminating erythrocytes were lysed in $0.2 \%(\mathrm{w} / \mathrm{v})$ saline for $30 \mathrm{~s}$. An equal volume of $1.6 \%$ $(\mathrm{w} / \mathrm{v})$ saline was added and the cells were again centrifuged $(500 \times \mathrm{g}$ for $10 \mathrm{~min})$. Neutrophils were washed in hydroxyethylpiperazine ethanesulphonic acid (HEPES)buffered Hank's balanced salt solution (HBSS) (HEPES $4.2 \mathrm{mM}, \mathrm{NaCl} 137 \mathrm{mM}, \mathrm{KCl} 2.6 \mathrm{mM}$, glucose $5.6 \mathrm{mM}$, $\mathrm{pH}$ 7.4) and resuspended in HEPES-HBSS supplemented with $\mathrm{CaCl}_{2}(1.3 \mathrm{mM})$ and $\mathrm{MgCl}_{2}(1 \mathrm{mM})$. Neutrophils were counted and diluted to $11 \times 10^{6}$ cells $\cdot \mathrm{mL}^{-1}$. Purity and viability were consistently $>95 \%$.

\section{Assay of acetyltransferase activity}

Acetyltransferase activity of neutrophils was assayed as described previously [24]. Briefly, unstimulated neutrophils, and neutrophils stimulated with $5 \mu \mathrm{M} \mathrm{Ca}^{2+}$ ionophore (A23187) to induce maximum acetyltransferase activity, were incubated at $37^{\circ} \mathrm{C}$ for $10 \mathrm{~min}$. Cells were centrifuged and resuspended in $0.25 \mathrm{M}$ sucrose containing $1 \mathrm{mM}$ dithiothreitol. They were disrupted

Table 1. - Lung function, oximetry and drug treatment for patients with acute asthma

\begin{tabular}{|c|c|c|c|c|c|c|c|c|}
\hline \multirow{2}{*}{$\begin{array}{l}\mathrm{Pt} \\
\text { No. }\end{array}$} & \multirow[b]{2}{*}{ Sex } & \multirow{2}{*}{$\begin{array}{l}\text { Age } \\
\text { yrs }\end{array}$} & \multirow{2}{*}{$\begin{array}{l}\text { Blood } \\
\text { taken }\end{array}$} & \multirow{2}{*}{$\begin{array}{c}\text { FEV1 acute } \\
\% \text { pred }\end{array}$} & \multirow{2}{*}{$\underset{\%}{\mathrm{Sa}_{\mathrm{a}, \mathrm{O}_{2}}}$} & \multirow{2}{*}{$\begin{array}{c}\text { FEV1 recovery } \\
\% \text { pred }\end{array}$} & \multicolumn{2}{|c|}{ Drug treatment } \\
\hline & & & & & & & Preadmission & Discharge \\
\hline 1 & $\mathrm{~F}$ & 19 & $\mathrm{a}, \mathrm{r}$ & 62 & 98 & 102 & ba & ba, pn, Bf, th \\
\hline 2 & $\mathrm{~F}$ & 32 & $\mathrm{a}, \mathrm{d}, \mathrm{r}$ & 38 & 93 & 122 & $\mathrm{ba}, \mathrm{Bc}$ & $\mathrm{ba}, \mathrm{pn}, \mathrm{Bc}$ \\
\hline 3 & $\mathrm{~F}$ & 19 & $\mathrm{a}$ & 58 & 95 & ND & ba, ip, Bf & $\mathrm{ba}, \mathrm{Bf}$ \\
\hline 4 & $\mathrm{~F}$ & 22 & $\mathrm{a}, \mathrm{r}$ & 41 & 98 & 93 & ba & $\mathrm{ba}, \mathrm{pn}, \mathrm{Bf}$ \\
\hline 5 & $\mathrm{~F}$ & 59 & $\mathrm{a}, \mathrm{d}, \mathrm{r}$ & 53 & 91 & 90 & ba, th & $\mathrm{ba}, \mathrm{pn}, \mathrm{Bf}$ \\
\hline 6 & M & 31 & $\mathrm{a}, \mathrm{d}, \mathrm{r}$ & 22 & 90 & 78 & $\mathrm{ba}, \mathrm{Bc}$ & $\mathrm{ba}, \mathrm{pn}, \mathrm{Bf}$ \\
\hline 7 & $\mathrm{~F}$ & 25 & $\mathrm{a}$ & 16 & 94 & ND & ba & $\mathrm{ba}, \mathrm{ip}, \mathrm{pn}, \mathrm{Bf}$, th \\
\hline 8 & $\mathrm{~F}$ & 69 & $\mathrm{a}, \mathrm{d}, \mathrm{r}$ & 53 & 99 & ND & ba, pn, bu & $\mathrm{ba}, \mathrm{Bf}$ \\
\hline 9 & M & 58 & $\mathrm{a}, \mathrm{d}, \mathrm{r}$ & 22 & ND & 95 & ba, pn, th & ba, pn, Bf, th \\
\hline 10 & $\mathrm{~F}$ & 28 & $\mathrm{a}$ & ND & 94 & ND & ba & $\mathrm{ba}, \mathrm{pn}, \mathrm{Bf}$ \\
\hline 11 & M & 29 & $\mathrm{a}, \mathrm{d}, \mathrm{r}$ & 38 & 92 & 92 & ba & ba, pn, Bf \\
\hline 12 & $\mathrm{~F}$ & 47 & $\mathrm{a}, \mathrm{r}$ & 63 & 97 & 72 & ba, pn, th, Bf & $\mathrm{ba}, \mathrm{pn}, \mathrm{th}, \mathrm{Bf}$ \\
\hline 13 & $\mathrm{~F}$ & 52 & $\mathrm{a}, \mathrm{d}, \mathrm{r}$ & 82 & ND & 78 & ba, pn, Bf & $\mathrm{ba}, \mathrm{pn}, \mathrm{Bf}$ \\
\hline 14 & $\mathrm{~F}$ & 47 & $\mathrm{a}, \mathrm{d}, \mathrm{r}$ & 31 & 98 & 49 & $\mathrm{ba}, \mathrm{Bf}$ & $\mathrm{ba}, \mathrm{pn}, \mathrm{Bf}$ \\
\hline 15 & $\mathrm{~F}$ & 48 & $\mathrm{a}, \mathrm{r}$ & 54 & ND & 91 & ba, ip, Bf, cr, th & $\mathrm{ba}, \mathrm{fp}, \mathrm{th}, \mathrm{cr}$ \\
\hline 16 & $\mathrm{~F}$ & 41 & $\mathrm{a}, \mathrm{d}, \mathrm{r}$ & 72 & ND & 87 & $\mathrm{ba}, \mathrm{sm}, \mathrm{fp}$ & $\mathrm{ba}, \mathrm{pn}, \mathrm{sm}, \mathrm{fp}$ \\
\hline
\end{tabular}

Pt: patient; F: female; M: male; a: acute; d: discharge; r: recovery; ND: not determined; ba: $\beta_{2}$-adrenoceptor agonists; Bc: Becotide; Bf: Becloforte; bu: budesonide; pn: prednisolone; fp: fluticasone propionate; th: theophylline; cr: cromoglycate; sm: salmeterol; ip: ipratropium bromide; FEV1: forced expiratory volume in one second; $\%$ pred: percentage of predicted value; $S_{\mathrm{a}, \mathrm{O}_{2}}:$ arterial oxygen saturation. Subjects from whom a blood sample was taken after recovery had ceased prednisolone for at least 2 weeks. 
by sonication for $20 \mathrm{~s}$ on ice, and the neutrophil lysates were assayed in duplicate for acetyltransferase activity in a reaction mixture containing lyso-PAF $(40 \mu \mathrm{M})$ and $\left[{ }^{3} \mathrm{H}\right]$ acetyl-CoA $(50-500 \mu \mathrm{M})$ in a final volume of 0.5 $\mathrm{mL}$ HEPES-HBSS containing $0.25 \%(\mathrm{w} / \mathrm{v})$ bovine serum albumin (BSA). After incubation at $37^{\circ} \mathrm{C}$ for $10 \mathrm{~min}$, the reaction was stopped by addition of methanol-chloroform-acetic acid (2:1:0.04, by volume). Lipids were extracted into chloroform [25], the extract was washed twice with $2 \mathrm{~mL}$ of $0.9 \%$ (w/v) saline-methanol-chloroform- $0.1 \mathrm{M}$ sodium acetate (1.0:2.5:3.75:1.0, by volume) and [acetyl- ${ }^{3} \mathrm{H}$ ]PAF was measured by liquid scintillation counting. Losses during lipid extraction were corrected for by extracting a control sample, to which [alkyl- $\left.{ }^{3} \mathrm{H}\right] \mathrm{PAF}$ was added. The mean recovery was $84 \pm 4 \%$. Acetyltransferase activities were expressed as [acetyl- ${ }^{3} \mathrm{H}$ ]PAF produced (nmol $\cdot \mathrm{min}^{-1} \cdot \mathrm{mg}^{-1}$ protein) after subtraction of the radioactivity in blank incubations which contained no lyso-PAF. Protein concentrations of neutrophil lysates were determined using the Coomassie blue protein assay (Bio-rad, Hercules, CA, USA).

Acetyltransferase activity, as measured in this assay, has previously been shown to increase linearly over the range of protein concentrations used and also over the incubation period of $10 \mathrm{~min}$ [24]. In addition [acetyl$\left.{ }^{3} \mathrm{H}\right] \mathrm{PAF}$ produced in this assay has been characterized on the basis of co-chromatography with authentic PAF standards on thin layer chromatography (TLC) and high performance liquid chromatography (HPLC) and by stimulation of human platelet aggregation, which was inhibited by the specific PAF receptor antagonists WEB 2086 and STY 2108 [24].

\section{Analysis of data and statistics}

Acetyltransferase activity was measured over a range of acetyl-CoA substrate concentrations both for unstimulated and A23187-stimulated neutrophil lysates. For each subject, the maximal enzymatic activity $\left(V_{\max }\right)$ and the enzymatic affinity constant $(\mathrm{Km})$ for unstimulated and A23187-stimulated neutrophils were determined from double reciprocal plots of acetyltransferase activity $(1 / \mathrm{V})$ against acetyl-CoA concentration $(1 /[\mathrm{S}])$. Vmax and $\mathrm{Km}$ values during the acute episode, at the time of discharge and following recovery are presented as medians and interquartile range (25th to 75 th percentile). The degree of stimulation of acetyltransferase activity induced by A23187 was calculated as the ratio Vmaxstimulated/Vmax-unstimulated, and the change in $\mathrm{Km}$ following stimulation with A23187 was calculated as the ratio $\mathrm{Km}$-unstimulated/Km-stimulated. Differences in median $V_{m a x}$ and $K m$ values and ratios for the 16 patients with acute asthma, the nine patients at discharge and the 13 patients at recovery were evaluated for statistical significance by nonparametric analysis of variance (Kruskal-Wallis test) using the InStat computer program (GraphPad Software, San Diego, CA, USA). The MannWhitney test was used to compare Vmax and $\mathrm{Km}$ values and ratios with data obtained previously using identical methodology, for 20 nonasthmatic subjects [24]. For statistically significant differences $(\mathrm{p}<0.05)$, the differences in median values and the associated $95 \%$ confidence intervals $(95 \% \mathrm{CI})$ are presented.

\section{Results}

Acetyltransferase activity in unstimulated and A23187stimulated neutrophils increased with increasing acetylCoA substrate concentration, reaching a plateau at 200 $\mu \mathrm{M}$ acetyl-CoA (fig. 1). For each subject, $V_{\max }$ and $\mathrm{Km}$ values were determined from double reciprocal plots, which did not deviate significantly from linearity, indicating that the enzyme followed Michaelis-Menten kinetics both in unstimulated and A23187-stimulated neutrophils for acetyl-CoA concentrations of 50-500 $\mu \mathrm{M}$ and a fixed lyso-PAF concentration $(40 \mu \mathrm{M})$. In the acute asthma group, the median $\mathrm{Km}$ for acetyltransferase in unstimulated neutrophils (93.8 (64.1-109.7) $\mu \mathrm{M}$; $\mathrm{n}=16$ ) was not significantly different to the value measured at discharge (104.6 (95.4-115.1) $\mu \mathrm{M} ; \mathrm{n}=9)$ or after recovery (107.2 (96.7-126.9) $\mu \mathrm{M} ; \mathrm{n}=13$ ) (fig. 2). However, an increase in $\mathrm{Km}$ was observed in 10 of the

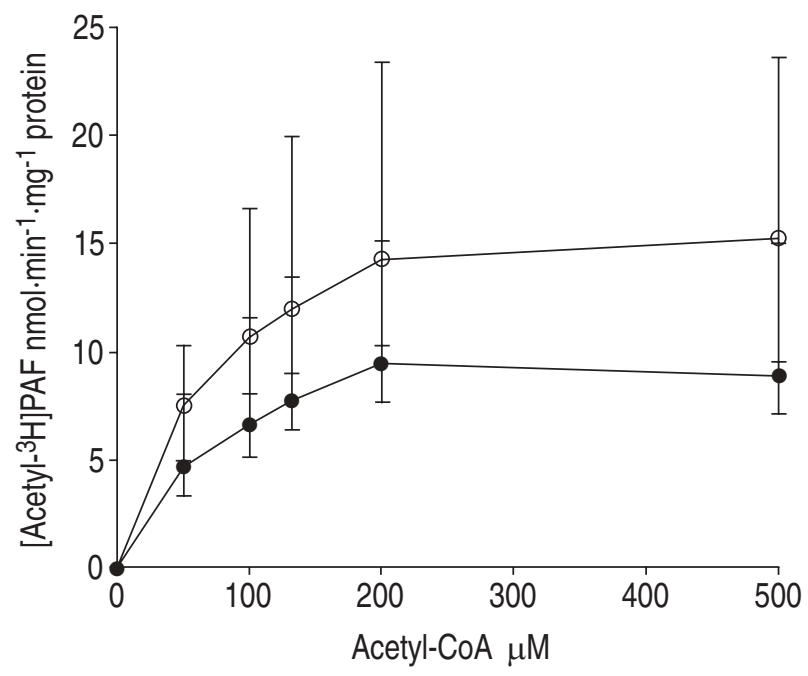

Fig. 1. - Lyso-PAF acetyltransferase activity as a function of acetylCoA concentration in unstimulated (- - ) and A23187-stimulated (- - - ) neutrophils from patients with acute asthma. Values are medians and interquartile ranges of data from 16 patients. PAF: plateletactivating factor; CoA: coenzyme A.

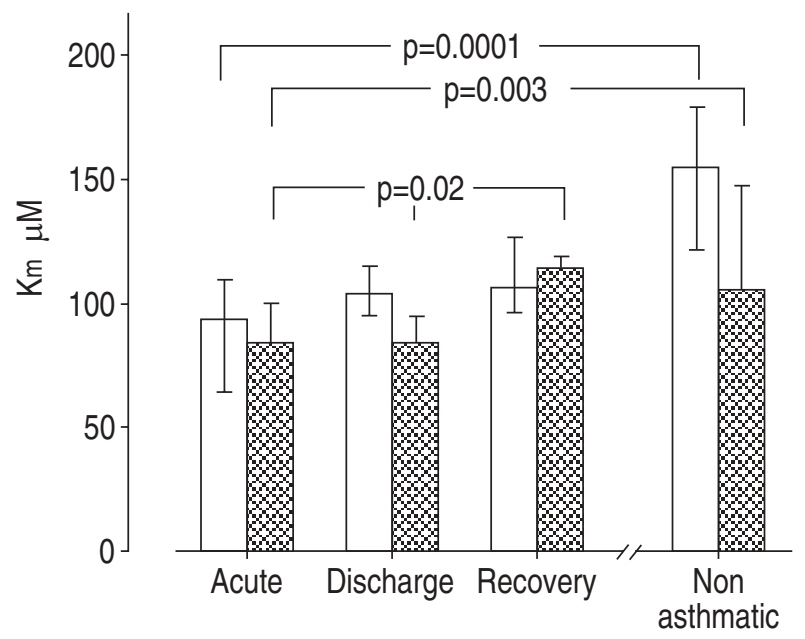

Fig. 2. - Median (interquartile range) $\mathrm{Km}$ values for acetyltransfe-


from patients with acute asthma $(n=16)$, at discharge $(n=9)$, and after recovery $(n=13)$, compared with the values measured previously [24] in nonasthmatic subjects $(n=20)$. Km: enzymatic affinity constant. 
13 subjects for whom $\mathrm{Km}$ was measured both during the acute stage and after recovery, 8 weeks later (fig. 3a). The median $\mathrm{Km}$ in acute asthma was significantly lower than the Km values measured previously [24] in nonasthmatic subjects using identical methods (155.1 (122.2-179.9) $\mu \mathrm{M} ; \mathrm{p}=0.0001$; median difference -64.9 (95\% CI -98.4 to -38.4$) \mu \mathrm{M}$ ) (fig. 2).

In acute asthma, at discharge and after recovery, median $\mathrm{Km}$ values for A23187-stimulated neutrophils did not differ significantly from the values for unstimulated neutrophils (fig. 2), although A23187 stimulation was previously shown to cause a significant reduction in $\mathrm{Km}$ in nonasthmatic subjects [24]. In A23187-stimulated neutrophils, the median $\mathrm{Km}$ values in acute asthma (84.3 (73.6-100.2) $\mu \mathrm{M})$ and at discharge (83.9 (83.194.8) $\mu \mathrm{M}$ ) were similar, although the median $\mathrm{Km}$ after recovery was increased $(115.0(95.6-119.5) \mu \mathrm{M} ; \mathrm{p}=0.02$, analysis of variance. The $\mathrm{Km}$ for A23187-stimulated cells in acute asthma was also significantly lower than the value measured previously in nonasthmatic subjects (106.6 (98.1-148.7) $\mu \mathrm{M}$; $\mathrm{p}=0.003$; median difference 27.8 (95\% CI -48.4 to -13.6$) \mu \mathrm{M}$ ) (fig. 2 ).

The change in $\mathrm{Km}$ following in vitro stimulation was measured as the ratio $\mathrm{Km}$ unstimulated/Km-stimulated.
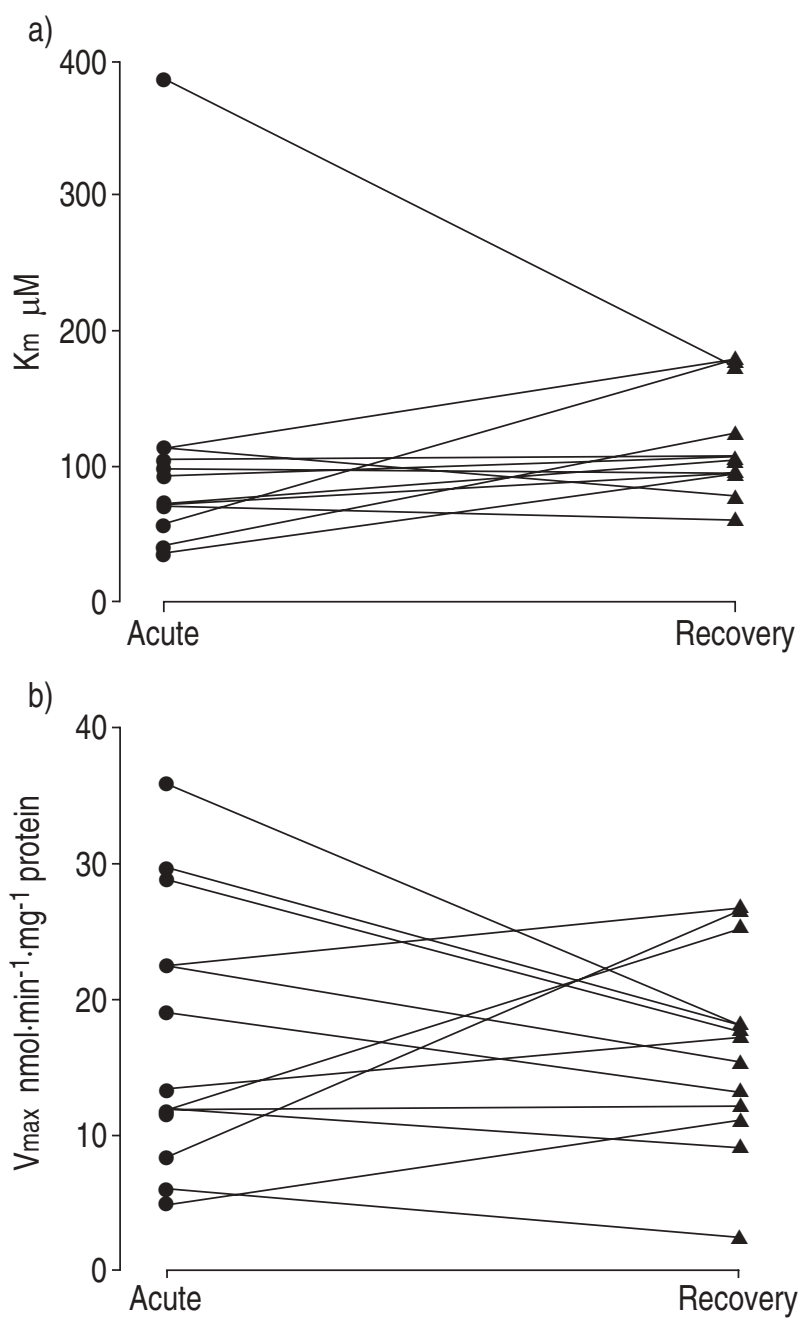

Fig. 3. - Changes in: a) Km; and b) Vmax values for neutrophil acetyltransferase in the 13 asthmatic patients for whom measurements were made both during the acute episode and following recovery. $\mathrm{Km}$ : enzymatic affinity constant; Vmax: maximal enzymatic activity.
Table 2. - Ratios $\mathrm{Km}$-unstimulated/Km-stimulated and Vmax-stimulated/Vmax-unstimulated in patients with acute asthma, at discharge and following recovery

\begin{tabular}{|c|c|c|c|c|c|}
\hline Group & $\begin{array}{c}\mathrm{Pt} \\
\mathrm{n}\end{array}$ & $\begin{array}{c}\text { Median } \\
\mathrm{Km} \\
\text { ratio }\end{array}$ & IQR & $\begin{array}{c}\text { Median } \\
\text { Vmax } \\
\text { ratio }\end{array}$ & IQR \\
\hline Acute asthma & 16 & $0.94 *$ & $0.80-1.08$ & 1.59 & $1.16-2.11$ \\
\hline Discharge & 9 & 1.06 & $1.01-1.35$ & 1.61 & $1.10-1.95$ \\
\hline Recovery & 13 & $0.95^{\dagger}$ & $0.88-1.15$ & 1.68 & $1.50-1.91$ \\
\hline $\begin{array}{l}\text { Nonasthmatic } \\
\text { (previous study) }\end{array}$ & 20 & 1.31 & $1.12-1.61$ & 2.07 & $1.60-2.59$ \\
\hline
\end{tabular}

Values significantly different to corresponding value previously measured in nonasthmatic subjects [24]: *: median difference -0.39 (95\% CI -0.62 to -0.19$) ; \mathrm{p}=0.003 ;$ : median difference -0.33 (95\% CI -0.53 to -0.1$), \mathrm{p}=0.006$; $:$ median difference -0.46 (95\% CI -0.88 to -0.06$), \mathrm{p}=0.029$. Km: enzymatic affinity constant; $V_{\max }$ maximal enzymatic activity; IQR: interquartile range; 95\% CI: 95\% confidence interval.

Median $\mathrm{Km}$ ratios did not differ significantly during acute asthma, at discharge or after recovery, but the ratios both during acute asthma and after recovery were significantly lower than the median $\mathrm{Km}$ ratio measured previously in nonasthmatic subjects [24] (table 2).

At all acetyl-CoA concentrations, acetyltransferase activities of unstimulated and A23187-stimulated neutrophils from patients with acute asthma did not differ significantly from values measured at discharge or following recovery. In addition, although there was a trend for the median Vmax for unstimulated neutrophils to increase from $12.9(10.5-22.5) \mathrm{nmol} \cdot \mathrm{min}^{-1} \cdot \mathrm{mg}^{-1}$ protein in acute asthmatic patients to 14.4 (12.3-20.4) $\mathrm{nmol} \cdot \mathrm{min}^{-1} \cdot \mathrm{mg}^{-1}$ protein at discharge, and $17.3(12.3-18.4)$ $\mathrm{nmol} \cdot \mathrm{min}^{-1} \cdot \mathrm{mg}^{-1}$ protein after recovery, with a corresponding reduction in the interquartile ranges, these median $V_{\text {max }}$ values were not significantly different (fig. 4). Vmax decreased in seven and increased in six of the 13 subjects in whom it was measured both during the acute stage and after recovery (fig. $3 b$ ). The median

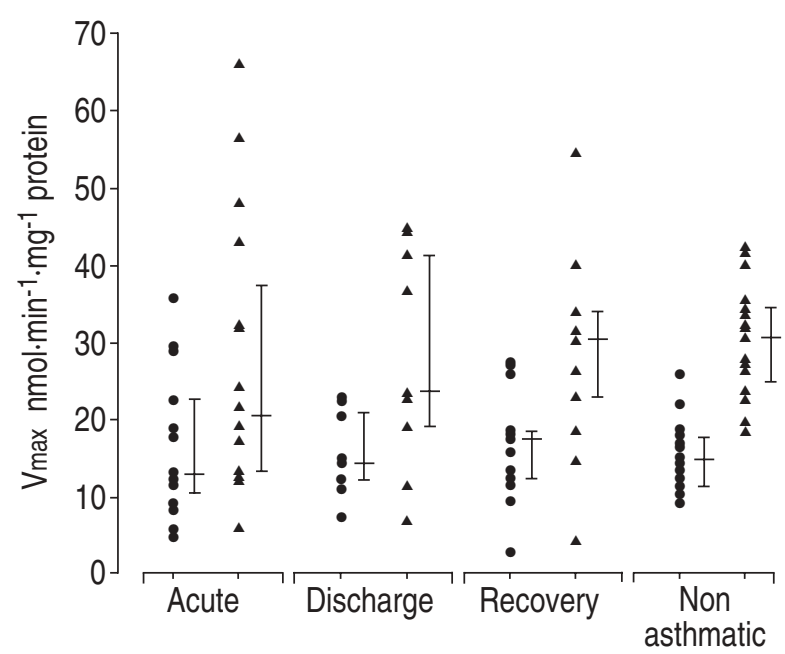

Fig. 4. - Scattergram showing Vmax values for acetyltransferase

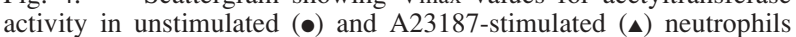
from patients with acute asthma $(n=16)$, at discharge $(n=9)$ and after recovery $(n=13)$. For comparison, the values previously measured [24] in nonasthmatic subjects $(\mathrm{n}=20)$ are also indicated. Bars indicate median values and interquartile ranges. Vmax: maximal enzymatic activity. 
Vmax value measured in acute asthmatic patients in this study was not significantly different to that measured previously [24] in nonasthmatic subjects (14.7 (10.9-17.4) $\mathrm{nmol} \cdot \mathrm{min}^{-1} \cdot \mathrm{mg}^{-1}$ protein $)$. There were no significant differences in the median Vmax values for A23187-stimulated neutrophils during acute asthma, at discharge or after recovery, and the values were also not significantly different to those measured previously in nonasthmatic subjects.

The degree of stimulation of acetyltransferase activity induced by A23187 was calculated for each subject as the ratio Vmax-stimulated/Vmax-unstimulated. The median Vmax ratios during acute asthma, at discharge and after recovery did not differ significantly but the V max ratio during acute asthma was significantly lower than that measured previously in nonasthmatic subjects (table 2 ). The $V \max$ ratio after recovery also differed from that of nonasthmatic subjects, although the difference did not quite reach statistical significance $(\mathrm{p}=0.06)$.

\section{Discussion}

Acetyl-CoA:lyso-PAF acetyltransferase activity was previously shown to be significantly increased in neutrophils from atopic, asthmatic subjects compared with a control group of nonasthmatic subjects [24]. The present study sought to extend these observations by measuring acetyltransferase activity of neutrophils obtained from patients experiencing symptoms of acute asthma. For most of these patients, it was possible to repeat the measurement of acetyltransferase activity after recovery from the acute episode, thus providing some indication of whether enzyme activity correlated with disease activity in asthmatic patients.

The median $\mathrm{Km}$ in acute asthma was significantly lower than that measured previously in healthy nonasthmatic subjects, thus confirming the trend towards a reduction in $\mathrm{Km}$ in stable asthmatic compared with nonasthmatic subjects [24]. Furthermore, in most acute subjects, the $\mathrm{Km}$ increased on recovery, suggesting that decrease in $\mathrm{Km}$ is a phenomenon associated with the acute asthmatic response. This was further supported by the observation that stimulation of neutrophils with A23187 resulted in very little change in median $\mathrm{Km}$ either during acute asthma or after recovery, contrasting with the significant reductions in $\mathrm{Km}$ following stimulation with A23187 of neutrophils from nonasthmatic and stable asthmatic subjects. These differences are highlighted by the ratios $\mathrm{Km}$-unstimulated/Km-stimulated, which were close to unity during acute asthma and after recovery but significantly higher in stable asthmatic and nonasthmatic subjects. Therefore, it appears that during acute asthma, neutrophil acetyltransferase undergoes a structural or conformational modification that increases the affinity of the enzyme for acetyl-CoA and renders it less susceptible to in vitro modulation by the $\mathrm{Ca}^{2+}$ ionophore A23187.

Lyso-PAF acetyltransferase in human neutrophils is activated and inactivated by a phosphorylation-dephosphorylation mechanism involving $\mathrm{Ca}^{2+}$-dependent protein kinase $C[26,27]$. As neutrophils circulate through the lungs of patients experiencing acute asthma symptoms, they may be primed by proinflammatory cytokines, such as granulocyte macrophage colony stimulating factor (GM-CSF), that are known to be present in the lungs of asthmatic patients [28], and this priming or activation may result in the modification of acetyltransferase and its function. It is also possible that PAF released systemically during acute asthma may itself feedback to modify neutrophil acetyltransferase with a resultant lowering of the $\mathrm{Km}$. An analogous desensitisation of platelets to in vitro stimulation by PAF has been observed following allergen inhalation by asthmatic patients, which presumably causes systemic PAF release in vivo [29].

However, the reduction in $\mathrm{Km}$ and increased substrate affinity during acute asthma does not appear to be associated with an increase in enzyme activity. Indeed, median Vmax appeared to be lower during acute asthma and, in contrast to the previously measured [24] activity in stable asthmatics, was not significantly greater than the activity in nonasthmatic subjects. However, the median Vmax appeared to increase at discharge and after recovery, although these changes were not statistically significant. The degree of stimulation obtained with A23187 as assessed by the ratio Vmax-stimulated/ Vmax-unstimulated was similar during acute asthma and after recovery but the ratios were smaller than those for non-asthmatic subjects. Thus, neutrophils from asthmatic patients appear to be inherently less sensitive to in vitro stimulation with A23187, supporting our previous findings [24].

It was possible that oral medications, such as corticosteroids and theophylline, administered either prior to or during the hospital admission may have influenced neutrophil acetyltransferase activity and the measurement of the enzyme activity at discharge was primarily performed in order to assess any such influence. The results indicating no significant differences in the $\mathrm{Km}$ and Vmax values at discharge compared with those measured during the acute stage and/or after recovery would suggest that the treatments received by these patients in hospital had little or no effect on acetyltransferase activity.

Studies with the oral PAF antagonists, WEB 2086 and modipafant, have shown little or no beneficial effect on lung function or asthma symptoms [30, 31], although a recent trial of another oral PAF antagonist, Y-24180 showed a significant reduction in bronchial hyperresponsiveness in asthmatic patients [32]. The importance of $\mathrm{PAF}$ as a mediator in asthma, therefore, remains controversial. While PAF may not be the primary effector in the asthmatic response, it may act as a priming agent in a network of lipid mediators and cytokines involved in the chronic inflammatory process [5, 19], and there is also evidence that systemic PAF concentrations are increased during acute asthma. A23187-stimulated granulocyte PAF production and plasma PAF levels are reported to be higher in children with asthma symptoms compared with asymptomatic or control children [16, 17], and in patients with mild asthma, blood PAF levels were increased following allergen-induced bronchoconstriction [15] and during spontaneous exacerbations [18].

Since in vitro studies indicate that acetyl-CoA:lysoPAF acetyltransferase regulates PAF production in human neutrophils and endothelial cells [33, 34], it might be predicted that increased systemic PAF concentrations 
in symptomatic asthma would result from upregulation of neutrophil acetyltransferase activity. However, the present study suggests that acetyltransferase activity is not increased, and may actually be reduced, during the acute episode compared with the activity in stable asthma. It is possible that increased inflammatory mediator or cytokine production consequent to the acute episode may initiate a negative feedback mechanism that reduces acetyltransferase activity as a means of controlling excessive PAF production. Following recovery, activity appeared to increase towards the chronically stimulated level previously observed in stable asthmatic subjects [24].

While upregulation of neutrophil acetyltransferase may, therefore, be involved in chronic PAF production in stable asthma, it may not be the major source of increased systemic PAF concentrations in acute asthma. It is possible that activated eosinophils in peripheral blood contribute significantly to systemic PAF production in acute asthma. Although the neutrophil preparations may have contained a few eosinophils, the present study does not permit any comment on whether acetyltransferase activity was increased in eosinophils alone, during acute asthma. Overall regulation of PAF biosynthesis in neutrophils may also depend on the activity of a CoA-independent transacylase in addition to lyso-PAF acetyltransferase $[35,36]$. Increased PAF production during acute asthma may, therefore, result from increased CoA-independent transacylase activity, and an increased supply of lyso-PAF substrate for acetyltransferase, the activity of which is already increased in stable asthma. Alternatively, increased systemic PAF concentrations in asthma may reflect a reduced rate of PAF degradation due to decreased activity of PAF acetylhydrolase. The activity of this enzyme in plasma is reportedly decreased in asthma [37], systemic lupus erythematosus [38], and septic shock [39]. Plasma PAF acetylhydrolase was recently cloned and the recombinant enzyme was shown to block inflammation in vivo, suggesting the possibility of its therapeutic use as an anti-inflammatory agent [40].

Although the present study did not indicate any increase in lyso-PAF acetyltransferase activity during acute asthma, $\mathrm{Km}$ was significantly reduced with a trend for $\mathrm{Km}$ and $\mathrm{Vmax}$ to increase on recovery. The change in the enzymatic affinity constant and maximal enzymatic activity following in vitro stimulation, was less in acute asthmatic patients compared with stable asthmatic and/ or nonasthmatic subjects and, taken together, these observations suggest that alterations in the regulation of enzyme activity may be occurring. Although the precise mechanisms regulating lyso-PAF acetyltransferase are unclear, this may occur at the protein and possibly at the gene level. Systemic and tissue PAF concentrations are likely to be determined by the overall balance between the activities of the biosynthetic and catabolic enzymes. Therefore, further studies are required of lysoPAF acetyltransferase activity and regulation in acute inflammation and in eosinophils, which are known to be associated with the development of airway hyperresponsiveness in asthma.

Acknowledgements: The authors thank T. Hamilton and the staff of the Department of Emergency Medicine at Sir Charles Gairdner Hospital, Perth, Western Australia for their assistance in performing this study.

\section{References}

1. Page CP. The role of platelet-activating factor in asthma. J Allergy Clin Immunol 1988; 81: 144-152.

2. Cuss FM, Dixon CMS, Barnes PJ. Effects of inhaled platelet-activating factor on pulmonary function and bronchial responsiveness in man. Lancet 1986; ii: 189-192.

3. Kaye MG, Smith LJ. Effects of inhaled leukotriene $\mathrm{D}_{4}$ and platelet-activating factor on airway reactivity in normal subjects. Am Rev Respir Dis 1990; 141: 993-997.

4. Wardlaw AJ, Moqbel R, Cromwell O, Kay AB. Plateletactivating factor: a potent chemotactic and chemokinetic factor for human eosinophils. J Clin Invest 1986; 78 : 1701-1706.

5. Kroegel C, Virchow JC Jr, Kortsik C, Matthys H. Cytokines, platelet-activating factor and eosinophils in asthma. Respir Med 1992; 86: 375-389.

6. Louis R, Degroote D, Bury T, et al. Changes in bronchial responsiveness, circulating leucocytes and ex-vivo cytokine production by blood monocytes after PAF inhalation in allergic asthmatics. Eur Respir J 1995; 8: 611-618.

7. Lai CKW, Jenkins JR, Polosa R, Holgate ST. Inhaled PAF fails to induce airway hyperresponsiveness to methacholine in normal human subjects. J Appl Physiol 1990; 68: 919-926.

8. Chung KF, Barnes PJ. Effect of inhaled platelet-activating factor on airway calibre, bronchial responsiveness and circulating cells in asthmatic subjects. Thorax 1989; 44: 108-115.

9. Evans TW, Chung KF, Rogers DF, Barnes PJ. Effect of platelet-activating factor on airway vascular permeability: possible mechanisms. J Appl Physiol 1987; 63: 479-484.

10. Lundgren JD, Kaliner M, Logun C, Shelhamer JH. Platelet-activating factor and tracheobronchial respiratory glycoconjugate release in feline and human explants: involvement of the lipoxygenase pathway. Agents Actions 1990; 30: 329-337.

11. Nieminen MM, Moilanen E, Nyholm JE, et al. Plateletactivating factor impairs tracheobronchial transport and increases plasma leukotriene $\mathrm{B}_{4}$ in man. Eur Respir $J$ 1991; 4: 561-570.

12. Valone F. Quantifying platelet-activating factor in biologic systems. J Allergy Clin Immunol 1993; 91: 551-552.

13. Stenton SC, Court EN, Kingston WP, et al. Plateletactivating factor in bronchoalveolar lavage fluid from asthmatic subjects. Eur Respir J 1990; 3: 408-413.

14. Miadonna A, Tedeschi A, Arnoux B, Sala A, Zanussi C, Benveniste J. Evidence of PAF-acether metabolic pathway activation in antigen challenge of upper respiratory airways. Am Rev Respir Dis 1989; 140: 142-147.

15. Chan-Yeung M, Lam S, Chan H, Tse KS, Salari H. The release of platelet-activating factor into plasma during allergen-induced bronchoconstriction. J Allergy Clin Immunol 1991; 87: 667-673.

16. Schauer U, Koch B, Michl U, Jager R, Rieger CHL. Enhanced production of platelet-activating factor by peripheral granulocytes from children with asthma. Allergy 1992; 47: 143-149.

17. Hsieh $\mathrm{KH}, \mathrm{Ng} \mathrm{CK}$. Increased plasma platelet-activating factor in children with acute asthmatic attacks and decreased in vivo and in vitro production of plateletactivating factor after immunotherapy. J Allergy Clin Immunol 1993; 91: 650-657.

18. Kurosawa M, Yamashita T, Kurimoto F. Increased levels 
of blood platelet-activating factor in bronchial asthmatic patients with active symptoms. Allergy 1994; 49: 60-63.

19. Chung KF. Platelet-activating factor in inflammation and pulmonary disorders. Clin Sci 1992; 83: 127-138.

20. Wirthmueller V, De Weck AL, Dahinden CA. Studies on the mechanism of platelet-activating factor production in GM-CSF primed neutrophils: involvement of protein synthesis and phospholipase $\mathrm{A}_{2}$ activation. Biochem Biophys Res Commun 1990; 170: 556-562.

21. McIntyre TM, Zimmerman GA, Satoh K, Prescott SM. Cultured endothelial cells synthesize both platelet-activating factor and prostacyclin in response to histamine, bradykinin and adenosine triphosphate. J Clin Invest 1985; 76: 271-280.

22. Valone FH, Epstein LB. Biphasic platelet-activating factor synthesis by human monocytes stimulated with IL$1 \beta$, tumor necrosis factor, or IFN- $\alpha$. J Immunol 1988; 141: 3945-3950.

23. Prescott SM, Zimmerman GA, McIntyre TM. Plateletactivating factor. J Biol Chem 1990; 265: 17381-17384.

24. Misso NLA, Gillon RL, Taylor ML, Stewart GA, Thompson PJ. Acetyl-CoA:lyso-platelet-activating factor acetyltransferase activity in neutrophils from asthmatic patients and normal subjects. Clin Sci 1993; 85: 455-463.

25. Bligh EG, Dyer WG. A rapid method of total lipid extraction and purification. Can J Biochem Physiol 1959; 37: 911-917.

26. Nieto ML, Velasco S, Sanchez Crespo M. Modulation of acetyl-CoA:1-alkyl-2-lyso-sn-glycero-3-phosphocholine (lyso-PAF) acetyltransferase in human polymorphonuclears: the role of cyclic AMP-dependent and phospholipid sensitive, calcium-dependent protein kinases. $J$ Biol Chem 1988; 263: 4607-4611.

27. Leyravaud S, Bossant MJ, Joly F, Bessou G, Benveniste J, Ninio E. Biosynthesis of PAF-acether. X. Phorbol myristate acetate-induced PAF-acether biosynthesis and acetyltransferase activation in human neutrophils. $J$ Immunol 1989; 143: 245-249.

28. Sousa AR, Poston RN, Lane SJ, Nakhosteen JA, Lee TH. Detection of GM-CSF in asthmatic bronchial epithelium and decrease by inhaled corticosteroids. Am Rev Respir Dis 1993; 147: 1557-1561.

29. Beer JH, Wuthrich B, von Felten A. Allergen exposure in acute asthma causes the release of platelet-activating factor (PAF) as demonstrated by the desensitization of platelets to PAF. Int Arch Allergy Immunol 1995; 106: 291-296.

30. Spence DPS, Johnston SL, Calverley PMA, et al. The effect of the orally active platelet-activating factor antagonist WEB-2086 in the treatment of asthma. Am J Respir Crit Care Med 1994; 149: 1142-1148.

31. Kuitert LM, Angus RM, Barnes NC, et al. Effect of a novel potent platelet-activating factor antagonist, modipafant, in clinical asthma. Am J Respir Crit Care Med 1995; 151: 1331-1335.

32. Hozawa S, Haruta Y, Ishioka S, Yamakido M. Effects of a PAF antagonist, Y-24180, on bronchial hyperresponsiveness in patients with asthma. Am J Respir Crit Care Med 1995; 152: 1198-1202.

33. Garcia MC, Fernandez-Gallardo S, Gijon MA, Garcia C, Nieto ML, Sanchez-Crespo M. Biosynthesis of platelet-activating factor (PAF) in human polymorphonuclear leucocytes. Biochem J 1990; 268: 91-98.

34. Holland MR, Venable ME, Whatley RE, Zimmerman GA, McIntyre TM, Prescott SM. Activation of the acetyl-coenzyme A:lysoplatelet-activating factor acetyltransferase regulates platelet-activating factor synthesis in human endothelial cells. J Biol Chem 1992; 267: 22883-22890.

35. Snyder F. Platelet-activating factor: the biosynthetic and catabolic enzymes. Biochem J 1995; 305: 689-705.

36. Venable ME, Nieto ML, Schmitt JD, Wykle RL. Conversion of 1-0-[ $\left.{ }^{3} \mathrm{H}\right]$ alkyl-2-arachidonoyl-sn-glycero-3-phosphorylcholine to lyso platelet-activating factor by the CoA-independent transacylase in membrane fractions of human neutrophils. J Biol Chem 1991; 266: 18691-18698.

37. Miwa M, Miyake T, Yamanaka T, et al. Characterization of serum platelet-activating factor (PAF) acetylhydrolase. J Clin Invest 1988; 82: 1983-1991.

38. Tetta C, Bussolino F, Modena V, et al. Release of platelet-activating factor in systemic lupus erythematosus. Int Arch Allergy Appl Immunol 1990; 91: 244-256.

39. Graham RM, Stephens CJ, Silvester W, Leong LL, Sturm MJ, Taylor RR. Plasma degradation of platelet-activating factor in severely ill patients with clinical sepsis. Crit Care Med 1994; 22: 204-212.

40. Tjoelker LW, Wilder C, Eberhardt C, et al. Anti-inflammatory properties of a platelet-activating factor acetylhydrolase. Nature 1995; 374: 549-553. 